\title{
ANALISA SESAR AKTIF MENGGUNAKAN METODE FOCAL MECHANISM (STUDI KASUS DATA GEMPA SEPANJANG CINCIN API ZONA SELATAN WILAYAH JAWA BARAT PADA TAHUN 1999-2009)
}

Oleh:

\author{
Siti Rahmatul Aslamiah Roemaf ${ }^{*}$
}

\begin{abstract}
ABSTRAK: Daerah Jawa Barat merupakan daerah yang tergolong rawan bencana gempabumi. Sejarah kegempaan di daerah ini menunjukkan ada 9 gempa merusak yang mengakibatkan banyaknya korban jiwa. Secara geografis daerah Jawa Barat terletak antara jalur mediteran (lempeng indoaustralia) dibagian selatan yang terbentang dari Sumatra, dan Jawa. Penelitian ini bertujuan untuk mengetahui orientasi bidang sesar atau patahan aktif. Untuk mengetahui mekanisme pergerakan sesar yang ditimbulkan oleh gempa bumi pada sepanjang cincin api zona selatan wilayah Jawa Barat khususnya dengan menggunakan metode mekanisme sumber (Focal Mechanism). Metode focal mechanism adalah ketika gempa bumi terjadi maka gelombang gempa bumi akan terpancarkan ke segala arah berbentuk phase gelombang. Penelitian ini membahas tentang analisa sesar aktif menggunakan metode focal mechanism (studi kasus data gempa sepanjang cincin api zona selatan wilayah Jawa Barat pada tahun 1999-2009). Untuk daerah yang menjadi obyek penelitian adalah dengan koordinat $5^{\circ} 50^{\prime}-7^{\circ} 50^{\prime}$ Lintang Selatan dan 104 $4^{\circ} 48^{\prime}-108^{\circ} 48^{\prime}$ Bujur Timur, termasuk kawasan selat sunda didalamnya. Data gelombang P diperoleh dari data United State Geological Survice (USGS) Colorado Amerika Serikat. Data tersebut diolah menggunakan software FOCMEC dan pemetaannya menggunakan Software winITDB. Hasil penelitian terhadap mekanisme sumber gempa ini, diketahui bahwa daerah Jawa Barat merupakan daerah yang rawan bencana gempabumi. Dari 10 tahun data penelitian terdapat 9 data gempa dengan magnitude $>6$ skala richter. Dari 9 data gempa yang di peroleh terdapat beberapa jenis sesar yaitu 4 sesar turun (normal), 3 sesar naik (reverse) dan 2 sesar mendatar (strike-slip). Dengan potensi bencana seperti ini diharapkan pemerintah daerah lebih cermat dalam melakukan pengembangan daerah serta usaha mitigasi bencana
\end{abstract}

Kata Kunci: Sesar, Mekanisme sumber

\section{PENDAHULUAN}

Indonesia yang terdiri dari ribuan pulau sangat rawan gempa karena berada di lebih dari satu lempeng bumi (lempeng Eurasia, lempeng pasifik, dan lempeng Filipina) yang berdekatan dengan lempeng Australia. Lempeng tersebut merupakan lempeng tektonik bumi yang masih aktif yang saling bertumbukan satu sama lain, dan di tambah pula adanya gunung-gunung berapi yang masih aktif sejumlah kurang lebih 129 buah yang berpotensi juga berpotensi terjadinya gempa. Gempa bumi terjadi karena gesekan dan tumbukan antara lempeng-lempeng tektonik yang berada jauh di bawah permukaan bumi. Pergeseran ini mengeluarkan energi yang luar biasa besar dan menimbulkan goncangan di permukaan [5].

\footnotetext{
* Mahasiswa Jurusan Fisika Fakultas Sains dan Teknologi UIN Maliki Malang
} 
Wilayah pantai selatan Provinsi Jawa Barat yang terletak dekat dengan pusat gempa bumi dan pada umumnya tersusun oleh endapan Kuarter, berupa endapan aluvium, endapan rombakan gunungapi, serta endapan tersier yang sebagian telah mengalami pelapukan, sehingga bersifat memperkuat efek goncangan gempa bumi. Wilayah yang tersusun oleh endapan kuarter tersebut akan mengalami goncangan gempa bumi lebih kuat dibandingkan wilayah lainnya.

Gempa Bumi yang terjadi di provinsi Jawa Barat menarik untuk dijadikan daerah penelitian. Melalui penelitian ini diharapkan dapat diketahui orientasi bidang sesar atau patahan di provinsi Jawa Barat, yang antara lain meliputi penentuan harga Strike, Dip, dan Rake.

Teori tektonik lempeng membagi bagian bumi menjadi dua lapisan.lapisan paling luar disebut lapisan litosfer, bersifat dingin dan kaku (rigid). Di bawah litosfer ini ada lapisan astenosfer yang panas dan mudah mengalami perubahan bentuk meskipun tidak cair, dan dapat mengalir dibawah pengaruh tegangan. Lapisan litosfer ini seolah-olah "hanyut" diatas astenosfer, sehingga terjadi gerakan saling meregang dan gerakan saling menekan. Akibat pergerakan lempeng ini maka di sekitar perbatasan lempeng terjadi akumulasi energi. Jika tidak bisa ditahan energi itu akan terlepas yang menyebabkan patahan atau deformasi pada lapisan kerak bumi dan terjadilah gempa tektonik [2].

Mekanisme gempa bumi dikontrol oleh pola penjalaran gelombang seismik di dalam bumi. Pola mekanisme ini tergantung pada pola medium penjalaran atau keadaan struktur kulit bumi serta distribusi gaya atau stress yang terjadi. Dalam menjelaskan gelombang seismik, asumsi dasar yang dipakai dalam memandang bumi yakni bumi di anggap sebagai media elastik sempurna yang terdiri dari berbagai lapisan dan Semua lapisan bumi merupakan media homogen isotropik dimana diskontinyuitas tahanan jenis hanya terdapat pada batas udara dan bumi.

Gelombang seismik menurut tempat penjalarannya dibagi menjadi dua gelombang yakni, pertama, gelombang dalam/badan (Body Waves) merupakan gelombang yang menjalar melalui bagian dalam bumi dan biasa disebut free wave karena dapat menjalar ke segala arah didalam bumi. Gelombang ini dapat di bedakan lagi atas dasar caranya merambat menjadi gelombang longitudinal atau gelombang primer (di singkat gelombang P) dan gelombang transversal atau gelombang sekunder (di singkat gelombang S). 


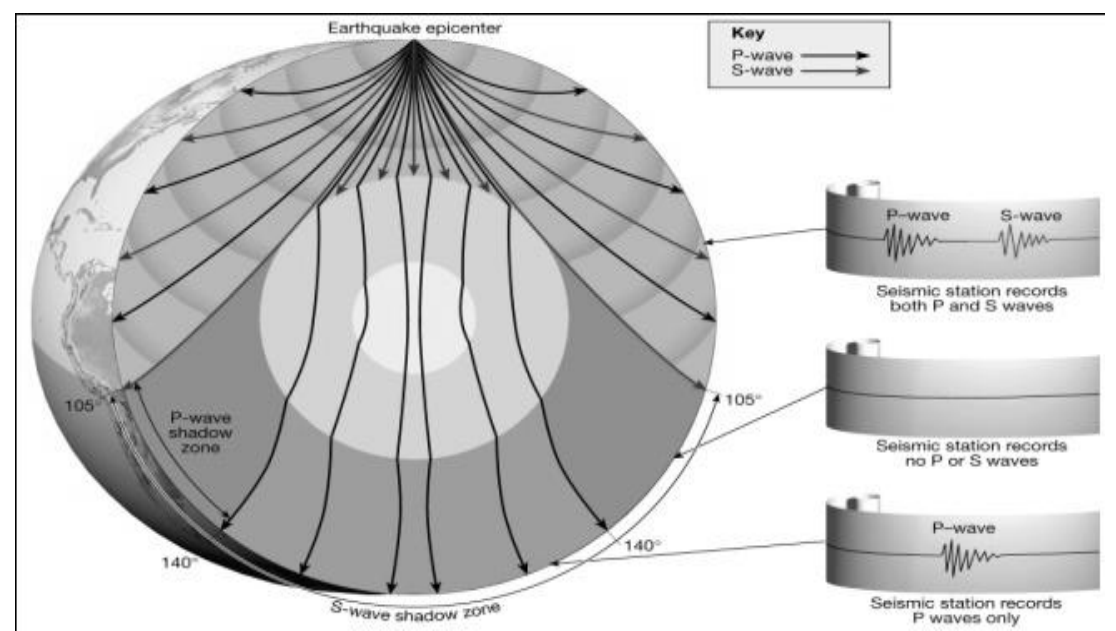

Gambar 1. Penjalaran Gelombang Body

Kedua, gelombang permukaan (surfaces waves) merupakan gelombang seismik yang menjalar sepanjang permukaan bumi. Gelombang permukaan inilah yang menyebabkan kerusakan di permukaan bumi terjadi gempa bumi. Gelombang permukaan dibagi atas gelombang Reyleigh (R) dan gelombang Love (L). Gerakan gelombang Reyleigh (R) menyerupai ellips dan bidang ellipsnya berdiri vertikal dan berhimpit dengan arah penjalaran gelombang. Gelombang ini terdeteksi setelah tibanya gelombang S pada arah vertikal [6]. Gelombang L terjadi apabila ada satu lapisan dengan kecepatan rendah menutupi lapisan yang mempunyai kecepatan yang lebih tinggi. Gerakan partikel sejajar bidang batas lapisan dan kecepatan gelombang ini merupakan fungsi dari panjang gelombang. Tidak ada gelombang permukaan dengan hanya gerakan SH dalam ruang paro seragam (uniform half surface) karena tidak mungkin dipenuhi pada kondisi bebas tegangan (stress-free) dengan hanya gerakan SH [6].

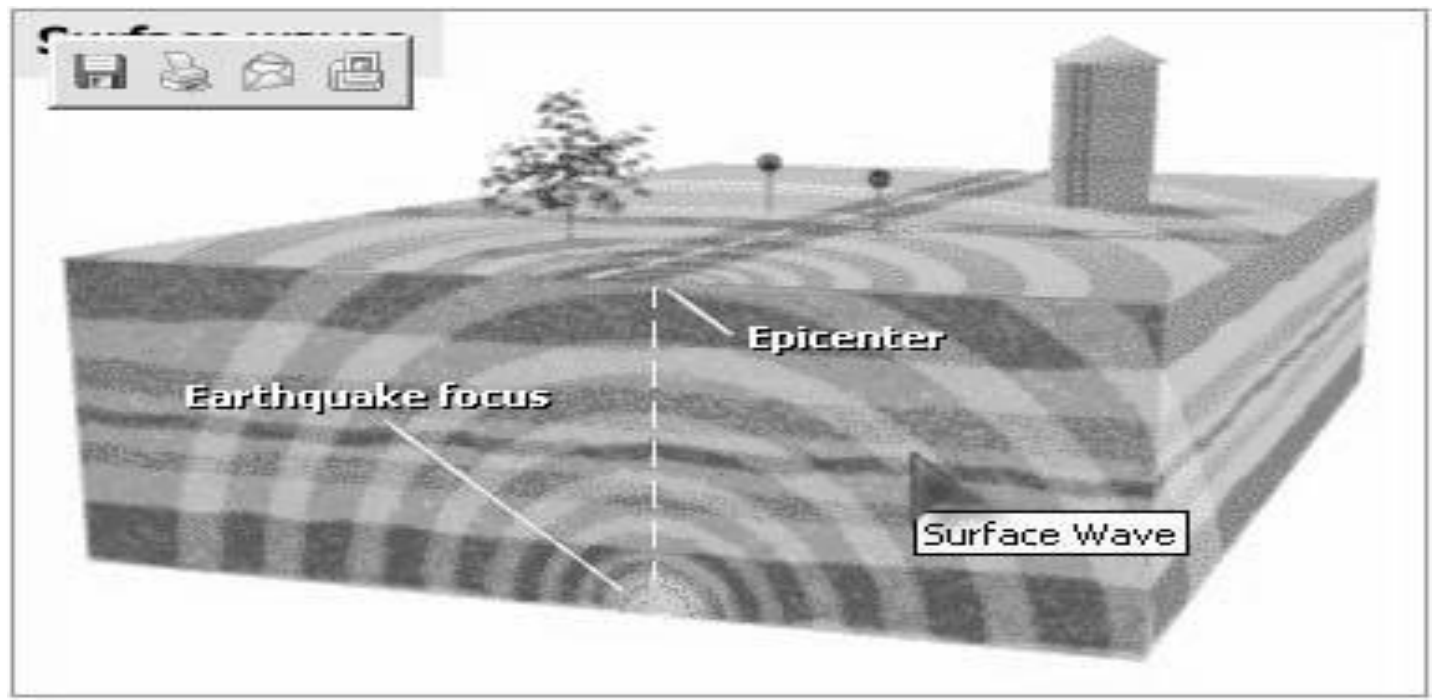

Gambar 2. Gelombang Permukaan anoname, tanpa tahun 
Penelitian ini dilakukan dengan pengambilan data gempa dari united state geological survice (USGS), penyortiran data sesuai dengan daerah target, jenis gelombang, dan pemberian nilai. Selanjutnya data sortiran ini dijadikan data masukan dan diolah dengan memakai software FOCMEC. Keluaran dari software FOCMEC berupa bola fokal. Bola ini selanjutnya dipetakan berdasarkan letak episentrumnya menggunakan software winITDB.

Bola fokal yang didapatkan memiliki bentuk tiga dimensi dan dianalisa arah gerakan aal gelombang P. Intepretasi secara visual dilakukan dengan cara membagi bola fokus menjadi dua bagian, bagian atas dan bawah. Kemudian setengah bola bagian bawah disinari dari bawah, sehingga didapatkan gambar bola dalam dua dimensi yang disebut dengan diagram bola fokus[2]. Langkah terakhir yakni dilakukan proyeksi pemetaan bidang sesar dalam diagram bola fokal untuk mendapatkan orientasi bidang sesar[3].

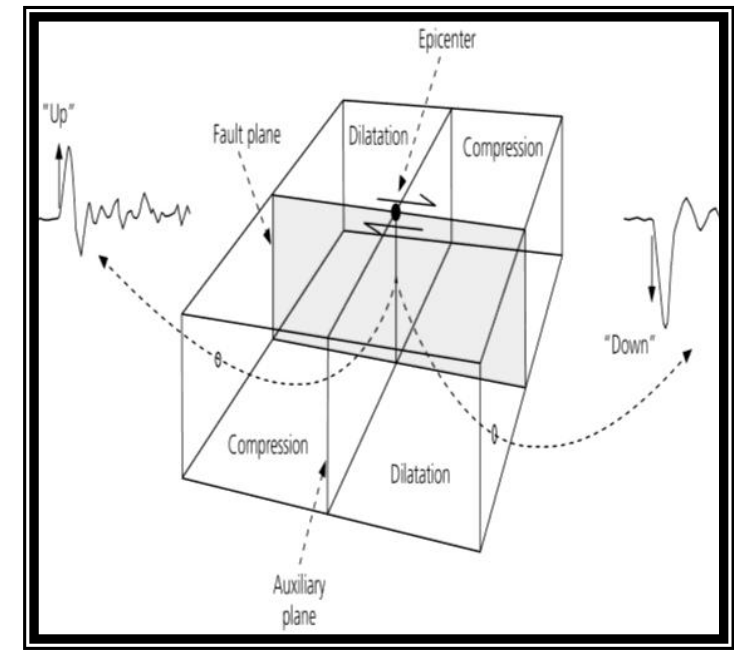

(a)

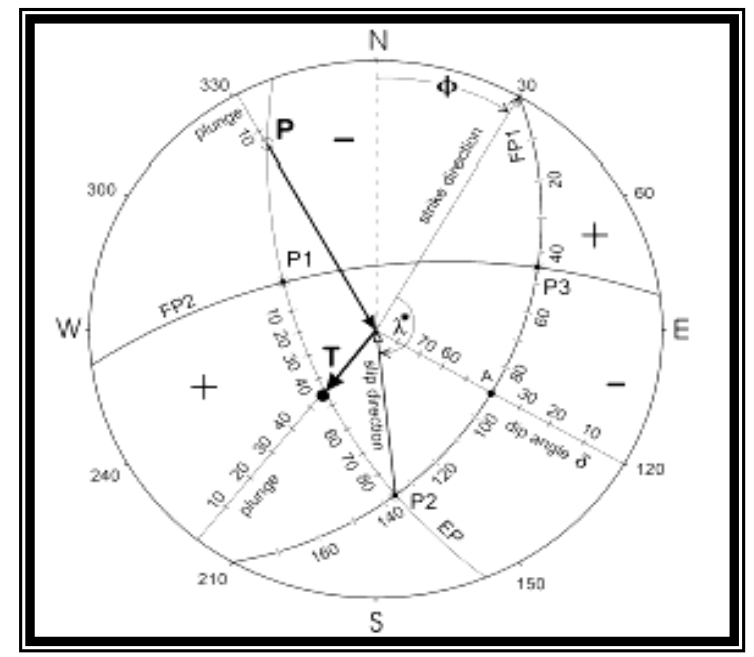

(b)

Gambar 3. (a) Hubungan antara polaritas gelombang P dengan arah bidang patahan (b) Parameter Orientasi Bidang Sesar pada Diagram Bola

\section{HASIL DAN PEMBAHASAN}

Untuk pengolahan data gempa dari penelitian ini digunakan software focmech dan untuk pemetaannya menggunakan software winITDB. Untuk tahap pertama pada pengolahan data dengan software ini adalah masuk kedalam program melalui command prompt. Hasil dari penelitian ini adalah berupa peta sebaran sesar yang ditunjukkan oleh bola fokal hasil penelitian. 

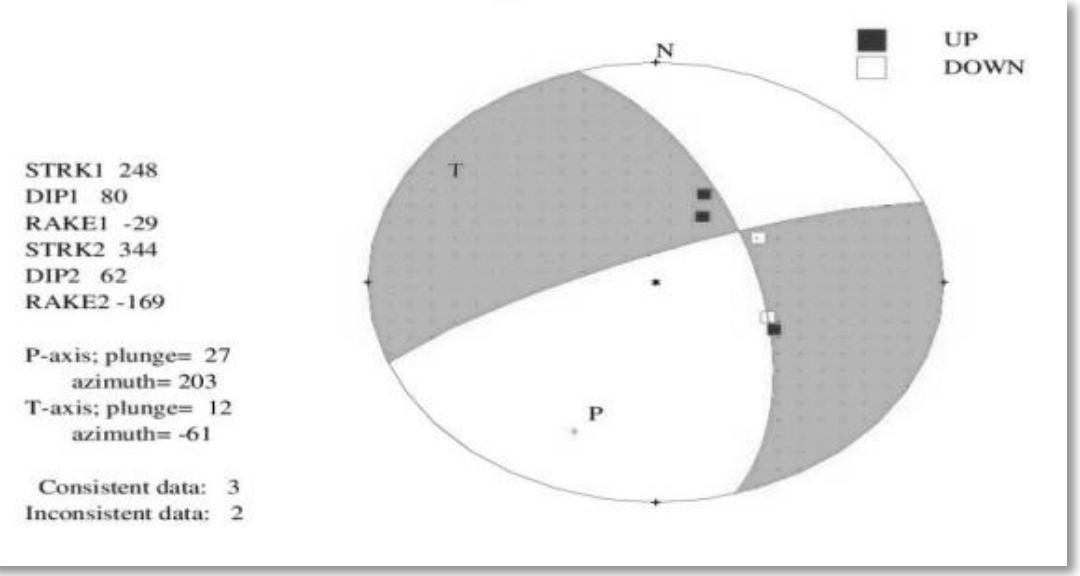

Gambar 4. Bola fokal

Zona atau daerah sesar yang paling sering menimbulkan gempa dari tahun 1999 sampai dengan tahun 2009 adalah:

Tabel 1. Zona gempa Jawa Barat

\begin{tabular}{|c|c|c|c|c|c|c|c|c|c|}
\hline No & $\begin{array}{c}\text { Even } \\
\text { Gempa }\end{array}$ & \multicolumn{2}{|c|}{ Episenter } & $\begin{array}{c}\text { Kedalaman } \\
(\mathrm{km})\end{array}$ & Strike & Dip & Rake & $\begin{array}{c}\text { Bola } \\
\text { Fokal }\end{array}$ & Ket \\
\hline 1 & $21 / 12 / 1999$ & 6.845 & 105.555 & 56.0 & 35 & 61 & 168 & & Reverse \\
\hline 2 & $25 / 10 / 2000$ & 6.549 & 105.630 & 38.0 & 357 & 59 & 32 & & $\begin{array}{c}\text { Strike } \\
\text { Slip }\end{array}$ \\
\hline 3 & $15 / 10 / 2002$ & 6.549 & 105.630 & 10.0 & 22 & 78 & -166 & & $\begin{array}{c}\text { Normal } \\
\text { Fault }\end{array}$ \\
\hline 4 & $15 / 01 / 2005$ & 6.462 & 105.236 & 58.7 & 187 & 84 & 18 & & \begin{tabular}{c} 
Reverse \\
\hline 5
\end{tabular} $16 / 10 / 2009$ \\
\hline
\end{tabular}

Zona ini termasuk zona yang cukup kompleks. Pada zone ini terdapat 5 even yang mana episenternya terletak didarat dan dilaut. Pertama, pada gempa tanggal 21 Desember 1999 memiliki bola fokal yang hampir sama dengan gempa tanggal 15 Januari 2005 yaitu sama-sama menunjukkan sesar naik. Pada 21 Desember 1999, gempa ini terjadi sekitar perairan selatan Ciaten. Karena untuk kuadran kompresi mengarah ke Pulau Deli, Pulau Tinjil dan Tanjung Palagan,. Untuk kuadran dilatasi mengarah ke Tanjung Panto, Cikiru Wetan, Sumurbatu, Mentayang dan Cibuluh. Gempa ini tergolong dalam gempa dangkal, sehingga berpotensi menimbulkan gelombang tsunami. 
Selanjutnya gempa tanggal 15 Januari 2005 letak episenternya di Selat Sunda. Sebaran kompresi mengarah ke sebalah utara Selat Sunda dan Samudera Hindia. Sedangkan dilatasinya mengarah ke Pulau Sumatera dan Tanjung Palagan. Kedua, untuk jenis sesar mendatar ada dua gempa, yaitu gempa yang terjadi pada 25 Oktober 2000 dan 16 November 2009. Untuk gempa pada tanggal 25 Oktober 2000, ini terjadi di daerah Larakawung, Kabupaten Banten. Daerah yang terkena dampak dari gempa tersebut Camara, Ciceureuheun, Karangbolong, Tanjung Palagan, Sumur, dan Cimanggu. Untuk kuadran kompresi mengarah ke Selat sunda dan Samudera Hindia. Sedangkan kuadran dilatasi mengarah ke Kabupaten Sukabumi dan pulau Panaitan. Gempa yang terjadi pada tanggal 25 Oktober 2000 merupakan gempa dangkal dengan kedalaman $38.0 \mathrm{~km}$, kemungkinan besar dapat menimbulkan gelombang tsunami. Sedangkan gempa tanggal 16 November 2009 yang mana letak episenternya berada di Pulau Panaitan. Untuk efek yang ditimbulkan dari gempa ini terdapat di Tanjung Waton, Tanjung Karangjajar, Tanjung Alangalang, Tanjung layar, Tanjung Guakolak, Tanjung Karang Bayang, Tanjung Palagan, Sumur, Cimanggu, Karangbolong, Camara dan Larakawung. Untuk sebaran kuadran kompresi mengarah ke Samudera Hindia dan Tanjung Palagan. Sedangkan, untuk kuadran dilatasi mengarah ke Selat Panaitan dan Selat Sunda. Gempa yang terjadi pada tanggal 16 November 2009 merupakan gempa dangkal dengan kedalaman 38.0 km, kemungkinan besar dapat menimbulkan gelombang tsunami.

Ketiga, gempa pada tanggal 15 Oktober 2002.Gempa ini terjadi di darat tepatnya disekitar Pulau Panaitan. Dilihat dari kuadran dilatasi mengarah ke Larakawung dan Selat Panaitan, kemudian untuk kuadran kompresinya mengarah ke Tanjung Alangalang dan Pulau Krakatau. Dan gempa ini menunjukkan sesar normal dan termasuk gempa dangkal dengan kedalaman $10.0 \mathrm{~km}$, sehingga berpotensi dapat menimbulkan gelombang tsunami.

Untuk melihat episenter dan bola fokal dapat dilihat pada peta dibawah ini.

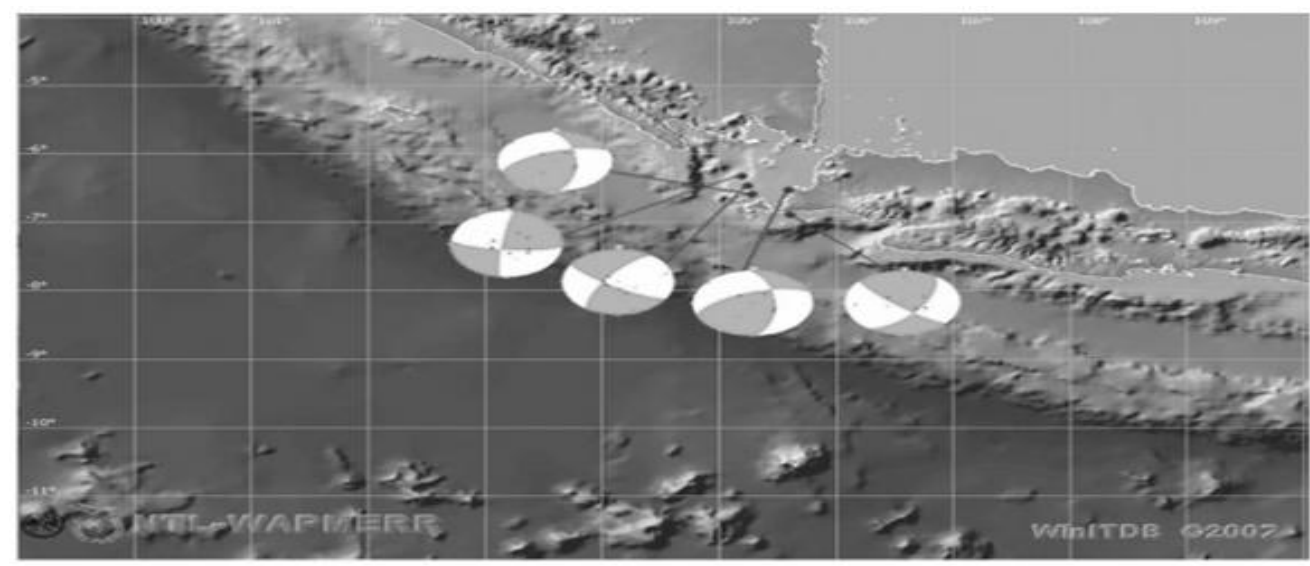

Gambar 5. Episenter dan bola fokal 
Pada penelitian mengenai analisa sesar aktif menggunakan metode focal mechanism (studi kasus data gempa sempanjang cincin api zona selatan wilayah Jawa Barat pada tahun 1999-2009). Dari hasil penelitian ini dapat disimpulkan bahwa daerah Jawa Barat termasuk daerah yang sering terkena bencana gempabumi. Dari 10 tahun data penelitian terdapat 9 data gempa dengan magnitude > 6 skala richter. Dari 5 data gempa yang di peroleh terdapat beberapa jenis sesar. Hal ini ditunjukkan dengan 1 sesar turun (normal), kemudian 2 sesar naik (reverse) dan 2 gempa menunjukkan sesar mendatar (strike-slip) di daerah Jawa Barat.

\section{KESIMPULAN}

Sesar-sesar pada bola okal menunjukkan arah gelombangnya, baik berupa kuadran kompresi maupun kuadran dilatasi yang terdapat di beberapa daerah pada propinsi Jawa Barat.

Mitigasi prabencana dapat dilakukan dengan melihat arah sebaran gelombang gempa, potensi dan keadaan geologi. Untuk pengembangan daerah diperlukan standarisasi bangunan tahan gempa, pengelolaan daerah pantai dan sosialisasi secara bertahap dan menyeluruh kepada masyarakat.

\section{DAFTAR PUSTAKA}

[1] Afnimar. 2009. Seismologi. Bandung: ITB.

[2] Prasetya, Tiar. 2006. Gempa Bumi. Yogyakarta: Gitanagari

[3] Rahmania, Merdiani, dkk. 2010. Penentuan Jenis Sesar Pada Gempabumi Sukabumi 2 September 2009 Berdasarkan Gerak Awal Gelombang P. Jurnal Penelitian.

[4] Mulyani, Lutfi Tri. 2006. Analisa Mekanisme Pusat Gempa Bumi Aceh Tanggal 26 Desember 2004. Tugas Akhir Tidak Diterbitkan. Jakarta: Akademi Meteorologi dan Geofisika.

[5] Dir. Vulkanologi dan Mitigasi Bencana; 2007

[6] Setiawan, 1993. Pengukuran Seismik 3 Kompopnen Dan Analisa Polarisasi Kegiatan Seismik Gunung Merapi Pada Saat Kubah Lava Tahun 1992, Thesis S2. UGM: Yogyakarta.

[7] Tjasyono, Bayong. 2009. Ilmu Kebumian dan Antariksa. Bandung: UPI. 